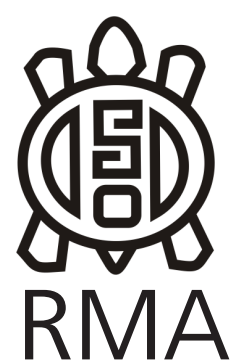

Arqueología

\title{
¿Manufactura, uso y descarte? 0 acerca del entramado social de los objetos cerámicos
}

\author{
Andrés Laguens* y Francisco G. Pazzarelli**
}

*CONICET, Museo de Antropología, Facultad de Filosofía y Humanidades, Universidad Nacional de Córdoba, Argentina. E- mail: laguens@ffyh.unc.edu.ar,

${ }^{*}$ CONICET, Museo de Antropología, Facultad de Filosofía y Humanidades, Universidad Nacional de Córdoba, Argentina. E-mail: fpazzarelli@hotmail.com

\begin{abstract}
Resumen
Si pensamos a las cosas y a los objetos como el resultado de un entramado multidimensional de acciones y relaciones, materiales e inmateriales, concretadas por agentes humanos y no humanos, resulta difícil seguir pensando a la materialidad de los objetos y del registro arqueológico en términos de procesos, como serie de fases sucesivas de acciones o conductas. Estos entramados entre las cosas y las personas son dinámicos, flujos constantes de acciones e interrelaciones, donde los objetos se constituyen como un efecto dinámico de las mismas; pero no en el sentido de sus causas, sino haciendo efectivas una serie de posibilidades dadas por las estrategias y los recursos puestos en juego, las disposiciones de los agentes participantes y su posición en un espacio social. Con estos criterios, no podemos pensar luego a los objetos y a sus contextos como el producto de acciones (conductas) y partes de un proceso, pues ya no existiría una cadena de comportamiento sino un fibrado de interrelaciones superpuestas, donde cada intersección es un lugar de mediación entre otras tantas acciones y relaciones. A través del análisis situacional y relacional de un conjunto de vasijas del Valle de Ambato (Catamarca, Argentina) mostraremos las potencialidades de un enfoque de este tipo para el estudio de la tecnología cerámica, más allá de sus procesos de manufactura, uso y descarte.
\end{abstract}

Palabras clave: Multidimensionalidad; Redes; Relaciones; Cerámica; Ambato.

¿Manufacture, use and disposal? Or about the social entanglement of ceramic objects

\begin{abstract}
If we think that things and objects are the result of a multidimensional bundle of actions and relationships, material or inmaterial, made by human and nonhuman agents, it is difficult to keep thinking about the materiality of objects and the archaeological record in terms of processes, as a series of successive phases of actions or behaviors. These bundles between things and people are dynamics, steady flows of actions and relationships, where objects are constituted as a dynamic effect of this relationships, not in the sense of their causes but making effective a series of possibilities given by the strategies and the resources involved, the disposition of the agents involved and their position in social space. With these criteria, then we can not think of objects and their contexts as the result of actions (behaviors) and parts of a process, no longer exist a chain of behavior but a bundle of overlapping relationships, where each intersection is a place of mediation among many other actions and relationships. Through a situational and relational analysis of a set of pots from the Ambato Valley (Catamarca, Argentina) we show the potential of this approach for the study of ceramic technology, beyond their manufacturing, use and disposal.
\end{abstract}

Keywords: Multidimensionality; Networks; Relationships; Pottery; Ambato.

Recibido 19-11-2011. Recibido con correcciones 01-12-2011. Aceptado 12-12-2011 


\section{Procuramiento -> Manufactura -> Transporte -> Uso}

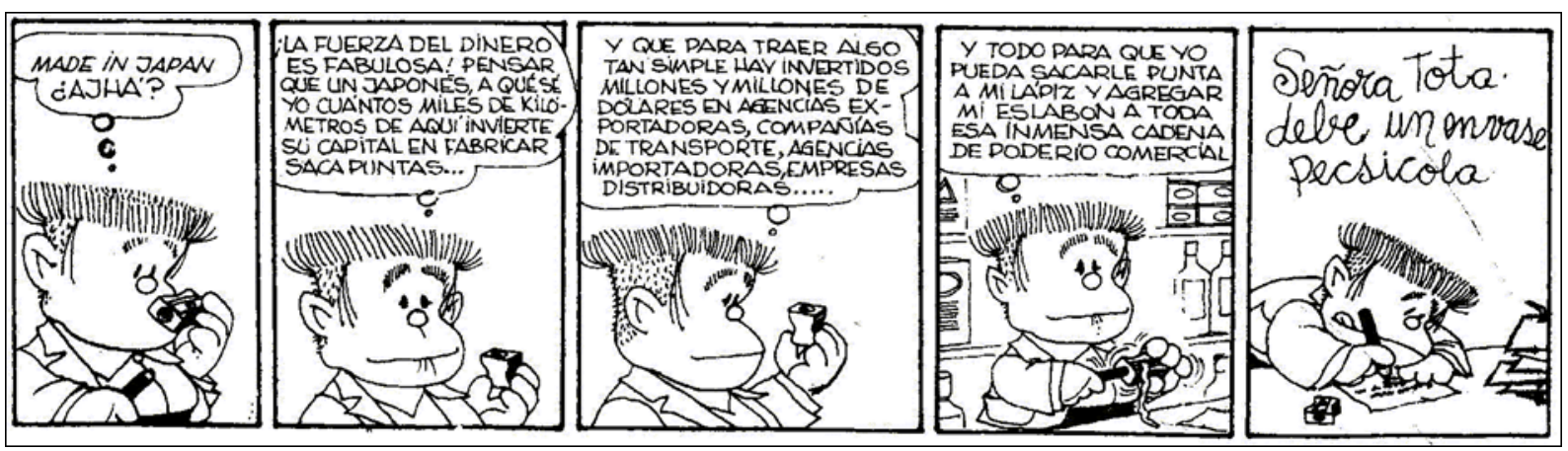

Figura 1. Redes / Figure 1. Networks.

\section{Los objetos como efectos de redes de relaciones}

De Japón a "Almacén Don Manolo": un nítido ejemplo de un proceso de cultura material desde la fabricación del sacapuntas en Japón a su funcionamiento en un almacén de barrio. Una "inmensa cadena de poderío"! (Figura 1)

Pero Manolito nos muestra algo más que una serie de pasos o eventos encadenados que se suceden hasta la satisfacción final del diseño de ese instrumento: sacarle punta a un lápiz. Nos muestra una inmensa red de relaciones, hasta casi sin sentido podríamos decir: un pequeño artefacto, fabricado en la antípoda, que llega a sus manos para facilitar la escritura de una nota de fiado a una clienta, por un envase de gaseosa de una empresa multinacional. Un inmensa red donde intervienen otros objetos y relaciones, desde objetos reificados (" ila fuerza del dinero!" dice Manolito), hasta un entramado de redes de redes (agencias exportadoras, compañías de transporte, agencias importadoras, otras distribuidoras, comercios minoristas, los que, a su vez, a través del funcionamiento del objeto, se entrecruzan finalmente con la Pepsi, con otras distribuidoras, con publicidad, con redes de mayoristas y minoristas, fletes, redes de consumo, sistemas de retorno y ciclado de envases, etc.). Podemos pensar entonces -junto con Manolito- que sacarle punta al lápiz resulta (y puede hacerse efectivo) por un entramado multidimensional de acciones y relaciones, materiales e inmateriales, concretadas por agentes humanos y no humanos, que abarcan variados espacios y tiempos.

Pero ello no es una característica sólo de los sacapuntas. El lápiz, la "pecsi", el diario, el papel y hasta el propio Manolito, como cualquier objeto, son cada uno y todos el efecto de una disposición durable de relaciones (Laguens 2008; Law 2000), esto es, un objeto es el efecto de una red y se mantendrá como tal mientras esas relaciones no cambien (Law 2000: 1). De la misma manera, una vasija usada para hacer chicha, por ejemplo, no sería sólo el producto de un proceso de manufactura y el resultado de un uso particular si su contexto cambiara. Éstas son sólo una o dos de sus redes posibles. En el objeto cerámico convergen, se entrecruzan, se solapan y se articulan una multiplicidad de redes, donde participan no sólo los artesanos, los usuarios o los propietarios de esa vasija, sino que también hay involucradas diversas relaciones humanas, otros agentes, otras actividades, varios procesos, a la par de otros artefactos, con otras redes, otros agentes, etc. de todo lo cual el objeto manufacturado resulta un efecto material. Es un efecto particular de una trama heterogénea de humanos y no humanos (Latour 1998).

Se trata del efecto de una disposición durable de relaciones, en tanto ciertas series de ellas se mantienen estables e inmutables, como las que hay entre las partes de una pieza, la estructura molecular lograda con la cocción, la relación entre los atributos estéticos o la decoración y la superficie; relaciones que permiten que el objeto siga siendo morfológicamente ese objeto mientras esas relaciones fijas y fijadas no se modifiquen. Esta propiedad de las relaciones permite que los objetos muebles circulen, sean trasladados y sigan manteniendo su estructura (lo que ha sido denominado móviles inmutables en la teoría del actor-red o ANT) (Law 2000).

Debe quedar claro que cuando decimos que los objetos son un efecto dinámico de esas acciones-relaciones, no lo hacemos en el sentido de sus causas, sino en el hecho que éstos hacen efectivas una serie de posibilidades dadas por las estrategias y los recursos materiales e inmateriales puestos en juego, las disposiciones de los agentes participantes en las prácticas materiales y su posición en un espacio social, históricamente situado.

La fijación de relaciones estables de algunos objetos permite que los mismos participen en distintos contextos relacionales, materiales y sociales, manteniendo su identificación como tales, más allá, como sabemos, de cómo cambia el sentido de un objeto de acuerdo a sus asociaciones y disposiciones espaciales en el registro arqueológico. Es decir, en su estabilidad, los objetos entran a participar en otras redes de relaciones, también heterogéneas, de cosas y personas. Es más, el mismo registro arqueológico es una red de relaciones, entre las 


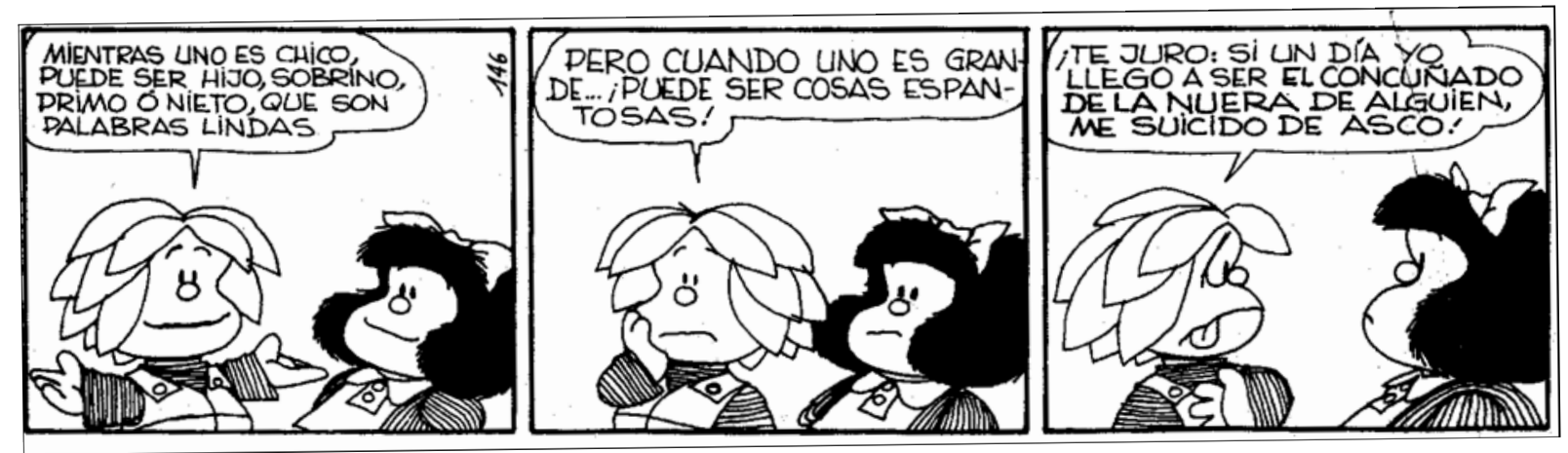

Figura 2. Relaciones / Figure 2. Relationships.

cuales podemos pensar al contexto arqueológico como una fracción de ella, como veremos más adelante.

Sin duda la idea de contexto como la propuso Schiffer (1972) ha resultado en un avance para pensar el registro arqueológico. La distinción entre un contexto arqueológico y otro sistémico, junto con la propuesta seminal de Binford (por ej., Binford 1980) de recuperar la dinámica del pasado a partir de la estática del presente del registro, son formas de pensar relacionalmente: la reconstrucción del pasado, las recomposición de cadenas conductuales, la caracterización de estrategias adaptativas, son todas distintas clases de inferencias realizadas a partir de las relaciones fijadas en, y recuperadas a partir de, el registro arqueológico. El gran tema aquí es cómo entendemos aquello que se está relacionando: qué es lo que se relaciona y cómo son esas relaciones.

\section{Pensar las relaciones relacionalmente}

Pensar las relaciones en términos de interacción - aquellas de los individuos que interactúan con el ambiente o las acciones que infligen sobre la materia para modificarlasupone pensar en sustancias, donde las cosas o las partes que intervienen poseen ciertas propiedades, que no son modificadas en su esencia por la relación con la otra parte (Emerbayer 1997, Laguens 2007). Por ello se habla de inter-acción y no de interrelación; las interacciones son relaciones entre individuos y cosas, realizadas a través de las acciones. De allí, por ejemplo, que la unidad mínima de una cadena de comportamiento sea una actividad, que recuperemos áreas de actividad en el registro arqueológico o que las conductas sean una serie de actividades pautadas (Figura 2).

De acuerdo a los diferentes contextos de interacción, los objetos adquirirán distintos significados y las relaciones involucradas permitirán distintas inferencias. La circulación de un objeto en su ciclo de vida a través de una cadena de comportamiento y su paso por distintos contextos, desde la manufactura hasta su descarte, resultan así en una visión performativa de las objetos de acuerdo a las interacciones o actividades en las que participaban. En una especie de performance o de "coreografía ontológica" (Hitchings 2003), la clasificación de los objetos en el contexto arqueológico respondería a la especificidad de las relaciones en las que operaba o funcionaba en el contexto sistémico. Al igual que desde la perspectiva de la contextualidad en arqueología (Hodder 1982, 1999) existe un cambio en el significado de los objetos de acuerdo al cambio de contexto, de los otros objetos/actores participantes y de las distintas interacciones que ello implicara.

Asimismo, si pensamos que el registro arqueológico es el producto y subproducto de estas acciones, conductas, o performances, ya sea desarrolladas linealmente en una cadena o proceso, o aún en procesos entrelazados en tramas de retroalimentación, estamos pensando casi en un solo plano de relaciones, aquél de interés o pasible de ser recuperado arqueológicamente. Pero pensar de manera relacional implica tratar de captar la simultaneidad de planos, de cosas y relaciones puestas en juego en cada cosa, en cada interrelación, recuperando así otras dimensiones y propiedades, fijas o dinámicas, que participan o se generan en la vinculación entre las partes.

Si logramos hacer una ruptura epistemológica y pensar relacionalmente, resulta difícil entonces seguir viendo a la materialidad de los objetos y del registro arqueológico sólo en términos de procesos, en tanto serie de secuencias sucesivas de acciones o conductas entrelazadas. Las conductas, las actividades y los procesos son únicamente una parte de un entramado relacional de los objetos y otras entidades, humanas y no humanas. La trama de relaciones en juego no se limita a un ordenado esquema de relaciones en una arena de interacciones sino que en realidad se asemeja más a las relaciones que se generan en un papel arrugado. Si antes modelábamos a las relaciones arqueológicas como una serie de cadenas entrecruzadas (por ejemplo, a la manera de un sistema tecnológico como nos propone Lemonnier -1986, 1992donde distintas cadenas operativas se entrecruzan en ciertos puntos nodales, en las que participan materiales, energía, conocimientos, conductas y representaciones sociales), ahora creemos que las relaciones arqueológicas se nos presentan como esto: un bollo de papel donde aquellas cosas que en un plano estaban separadas, ahora están próximas o se superponen, con una infinidad de planos que se chocan y se entrecruzan, una infinidad de 

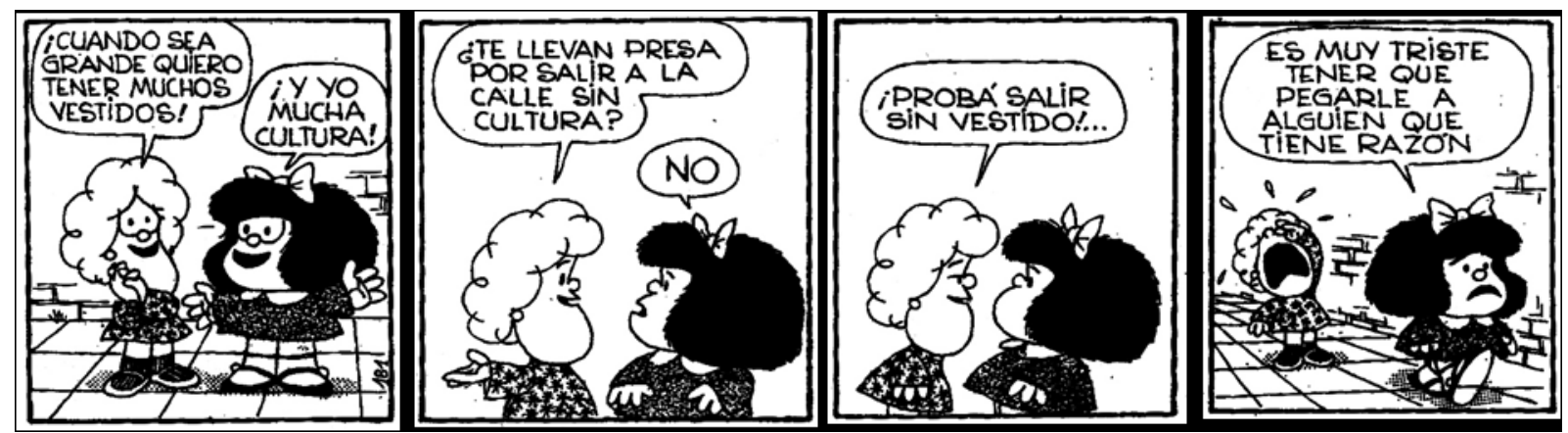

Figura 3. Agencias I/ Figure 3. Agencies I.

líneas de relaciones, más cortas, más largas, con cientos de puntos de intersección y con una multiplicidad de relaciones que antes no existían. Podemos intentar estirar el papel nuevamente, recurrir a nuestra metodología para plancharlo, pero las arrugas seguirán ahí. Las redes se pusieron en evidencia'.

Este modelo del papel arrugado nos permite vislumbrar que la red de relaciones donde se halla inmerso un objeto puede ser tan compleja y variada que se aproxima más a una especie de entretejido multiplanar o multidimensional. Por ello sería más apropiado y descriptivo que en vez de hablar de redes de relaciones, de entramado o de redes de redes, hablásemos de un fibrado de relaciones (Latour 1998). Un fibrado es una figura más pertinente pues posee una apariencia más desordenada que una red, con relaciones en muchas direcciones, con más de un punto de contacto sobre una misma fibra, con variados puntos de cruce, intersticios y distintas intensidades de ligazón, en contraste con una red fija de nodos y conexiones.

\section{La agencia de los objetos y de las personas}

Entendidos los objetos como un efecto de una serie de relaciones, algunas durables y otras variables, en un fibrado heterogéneo en las cuales participan humanos con capacidad de agencia, dijimos que se establecen interrelaciones entre las partes. Estas interrelaciones implican una vinculación activa entre las partes, en una especie de mutua agencia, donde una tiene la capacidad de influir sobre la otra. $Y$ decimos en una especie de agencia, ya que cuestionamos aún de la capacidad de agencia independiente de los objetos o, al menos, que sea el mismo tipo de agencia que la de los humanos, o si bien se trata de dos clases de agentes (Figura 3)

Hay consenso en cuanto a que la agencia es algo que se posee (sea una capacidad, una habilidad o una propiedad) y que tanto humanos como no humanos son candidatos a poseerla. Y también que la agencia se ejerce sobre o hacia

\footnotetext{
${ }^{1}$ Law (2000) sostiene que los objetos son como un origami: una serie de pliegues sucesivos, en donde se superponen relaciones, que van conformando una cosa, y donde cada pliegue adquiere sentido en función del otro. Nuestro modelo se aproxima más al del círculo dibujado en un pañuelo planchado y luego metido desordenamente en el bolsillo de Serres y Latour citado por Smith (2003).
}

algo, como otras personas, lugares, significados o eventos (Emirbayer 1997: 294). La dificultad en su asignación a los objetos residirá entonces en cómo la comprendamos.

Hay varias formas en que es entendida la agencia (Emirbayer 1997; Emirbayer y Mische 1998; Fuchs 2001). Si la agencia es entendida como algo que implica conciencia, reflexividad y libre elección (Fuchs 2001: 26), algunos dirían que se trata de algo exclusivamente humano. Es más, para algunos sería una propiedad esencial que tenemos las personas en tanto humanos, en cuanto "propiedades internas e intrínsecas o estados de personas, que definen lo que significa y cómo es, ser un actor humano" (Ibídem: 32).

Por lo común, la agencia es entendida como una atribución caracterizada como una instancia de intencionalidad, en una perspectiva sociológica, por la cual algunos colectivos sociales y entidades no humanas, como los animales, pueden poseerla (Ibídem). También algo puede recibir agencia desde un observador cuando éste comienza a creer que lo observado tiene alguna condición interna desde la cual piensa, imagina, decide y desea (Ibídem), como sucedería con en el animismo o el fetichismo (Descola 2000). En este último caso la agencia de los objetos sería entonces una propiedad asignada a ellos a partir de un tipo de relación.

Desde otro punto de vista relacional, la agencia también puede ser entendida no como una causa sino como un efecto de una estructura subyacente (Fuchs 2000: 34) o de un sistema estructurado de disposiciones socialmente incorporadas, como el habitus. En este sentido, se aproxima más a una variable dependiente de la dinámica de ciertas situaciones u ocasiones, que se manifestará más en ciertas redes que en otras, por la cual no todas las personas y no en cualquier momento tendrían capacidad de agencia.

Sin embargo, otras posiciones sostienen una perspectiva que no reconoce una distinción a priori entre entidades sino que postulan una simetría entre las mismas. Desde el punto de vista de la teoría del actor-red o ANT, se ha planteado una simetría generalizada (Ihde 2006; Verbeerk 2003), por lo que no habría diferencias de clase entre 
humanos y no humanos (Law 1992) y ambos constituirían un colectivo (Latour 1998) en el cual "las entidades toman su forma y adquieren sus atributos como resultado de sus relaciones con otras entidades. En este esquema de cosas, las entidades no tienen cualidades inherentes..." (Law 1997: 2), no existiendo divisiones esencialistas. Esta premisa de una simetría generalizada es la que sustenta también las propuestas de la arqueología simétrica que rechazan la división a priori entre "personas" y "cosas", argumentando que ambos deberían tratarse, al menos al inicio de una indagación, en términos de igualdad (Shanks 2006; Webmoor 2006; Witmore 2006).

Así, cualquier entidad que genere un efecto de relación, o tenga algún valor de significación, es considerado un agente (Tirado Serrano y Domenech i Argemí 2005: 11); en otras palabras, la agencia sería un producto de la misma red de relaciones que constituye a las entidades, por lo cual, tanto humanos como no humanos se encontrarían con la posibilidad de poseerla.

Sin embargo, cabe añadir algo importante: la agencia de los no humanos sólo puede tener lugar y ser conocida a través de la mediación de la percepción humana y del lenguaje (Breslau 2000); es decir, que si bien podemos aceptar la posibilidad de agencias en ambas clases de entidades, no se trataría de un único colectivo indiferenciado cuyas entidades se construyen en la interrelación: "Las diferencias entre la agencia humana y la no humana son [...] diferencias entre clases de agentes, más que entre humanos que actúan y objetos sobre los cuales se actúa" (Breslau 2000: 300).

Desde la antropología del arte, Layton afirma que la agencia es atribuible a las personas y cosas que son vistas como iniciando secuencias causales; un agente es la fuente, el origen, de eventos causales. Por lo tanto, los objetos de arte no pueden ser agentes en sí mismos sino que actúan meramente como extensiones (índices) de la agencia de sus hacedores o de sus usuarios. Los objetos no son agentes auto-suficientes, sino secundarios que tienen efecto en virtud de estar inmersos en relaciones sociales. La agencia de los objetos es una propiedad agregada humanamente (Figura 4).
Pero hay otra dimensión de las cosas en cuanto éstas tienen propiedades y generan efectos que van más allá de las intenciones de sus hacedores - tanto sean objetos de arte o no, objetos de naturaleza u objetos de cultura. Un árbol caído en un camino tiene un efecto sobre los transeúntes que afecta sus acciones; una vasija genera un espacio de inclusión y de exclusión en cuanto al lugar físico que ocupa, así como efecto visuales en los observadores, superando las intenciones de su creador.

Proponemos que quizás las nociones de agencia inherente, de influjo o de incidencia sean términos más apropiados para este poder de los objetos sobre otros elementos de las redes de relaciones. Los objetos, en virtud de sus propiedades (sean aquellas efecto de sus relaciones fijas -entre las que cuentan las atribuidas intencionalmente en su creación- o bien aquellas generadas en las redes donde participan) tendrán cierto poder para ejercer influencia sobre otras entidades con las cuales entren en relación, produciendo ciertos efectos o resultados que afectarán a la otra parte, sin que ello implique una intencionalidad o agencia propia del objeto. En cierto sentido, esta noción de agencia inherente se aproxima a la noción de cultura activa de Hodder (1994) y encuentra similitudes en la noción de affordances de Gibson (1971).

Esto, sin duda, implica un tratamiento asimétrico de las entidades, ya que los humanos tendrían agencia y los no humanos sólo incidencia, poder de influencia o una agencia agregada; al menos hasta que la reconstrucción de las redes de relaciones nos permita definir su propia agencia. Pero también es un recurso metodológico, al igual que la simetría generalizada los es para la teoría del actor-red. Así como la ANT y la arqueología simétrica nos proponen no establecer diferencias a priori entre las entidades, nosotros apuntamos a priori a tratar de entender los objetos por los objetos mismos². Si

\footnotetext{
2 Tratar de entender los objetos por los objetos mismos implica rematerializar lo material, re-materializar lo arqueológico, en tanto si bien se reconoce a la arqueología como un estudio de la cultura material (inclusive, en todo tiempo y lugar, según Schiffer 1976), paradójicamente, la perspectiva dominante y reproducida académicamente (desde antes de Kroeber, pasando por Binford hasta Hodder y después), es que en definitiva la cultura material es un medio para alcanzar aspectos no materiales de la cultura. Se trata de un nuevo (nuevo?)
}

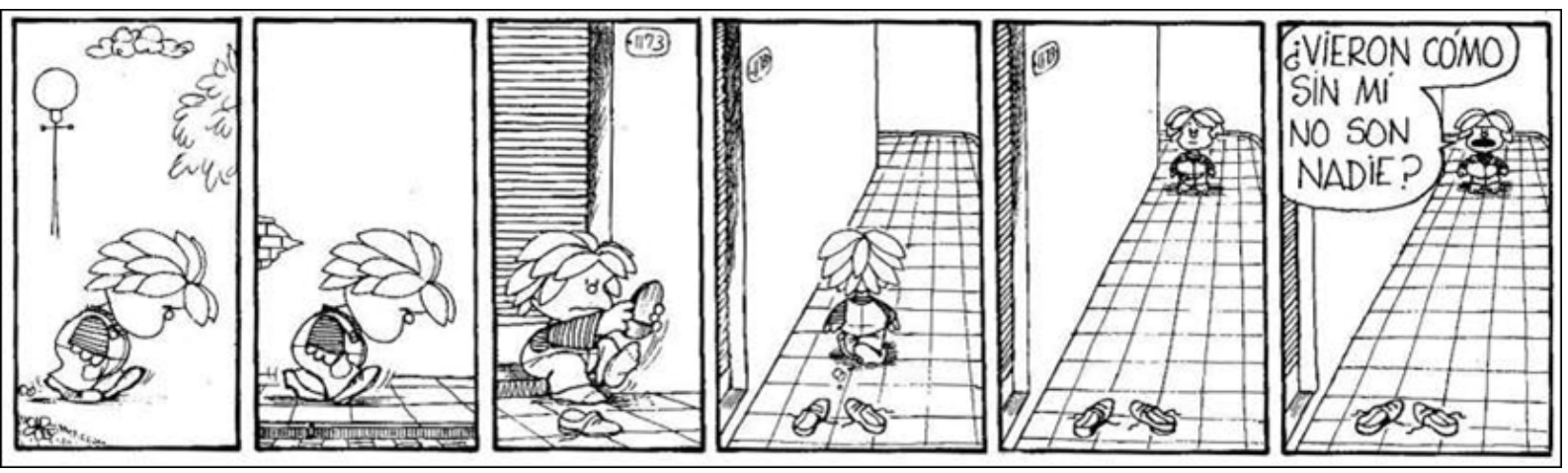

Figura 4. Agencias II / Figure 4. Agencies II. 
bien estamos convencidos que no hay un límite que pueda separar a lo humano de lo no humano o de los objetos, ya que ambos son y están mutuamente constituidos en su entramado de relaciones mutuas, ello no implica que tengan iguales propiedades y deban ser tratados por igual ${ }^{3}$. En una segunda instancia, cuando comprendamos las distintas relaciones particulares en que ambas entidades estén inmersas, propias de distintos grupos de personas o de fibrados particulares situados históricamente, podremos ponderar la simetría o no de las distintas clases de relaciones ${ }^{4}$ y la continuidad 0 discontinuidad entre humanos y no humanos.

\section{La multiplicidad y la simultaneidad de las agencias}

Aceptando que los objetos tienen una posibilidad de agencia o incidencia inherente sobre las otras entidades con las que entren en interrelación, debemos considerar que esta potencialidad no se limita sólo a esta clase de agencia, ya que los objetos pueden ser imbuidos con otras capacidades a partir de la intencionalidad de los humanos. Distintos agentes, con distintas predisposiciones estructuradas y en distintas posiciones del espacio social (Laguens 2006), no sólo entablarán diferentes relaciones con un objeto o una misma clase de objetos, sino que podrán imbuirles y atribuirles distintas agencias más.

Platonismo, donde los objetos son reducidos a algo no material pues lo primordial es aquello detrás de los objetos (Verbeerk y Kockelkoren 1998).

3 Es claro que no estamos a favor de una disolución de la "humanidad" de los humanos entre otras entidades, más allá que sepamos bien de qué se trata ser un humano o de cualquier posición filosófica del lector. Uno de los motivos es el riesgo político que puede implicar las derivaciones o interpretaciones no antropológicas de esta línea de pensamiento, respaldadas por trabajos arqueológicos. En la historia americana encontramos ejemplos acerca de humanos tratados como objetos (en el caso del sometimiento de indios y negros, por ejemplo) que aún tienen consecuencias en la actualidad en la gran mayoría de los países latinoamericanos. Otros motivos, son el riesgo del relativismo extremo justificado por los efectos generados por las redes y los problemas éticos que pueden surgir, por ejemplo, como cuando Emirbayer desde un punto de vista ético o político se pregunta ¿si los valores no son sustancias preconstituidas, cómo surgen entonces y cómo pueden ser evaluados? (Emirbayer 1997).

4 Para un ejemplo, Laguens y Gastaldi (2008) para las relaciones de identificación entre humanos y naturaleza en la cultura arqueológica Aguada
Por su parte, un objeto suele estar vinculado con otros objetos, ya sea en la inmediatez de un contexto espacial cercano o en redes espacialmente más extensas, los que a su vez tendrán sus propias agencias inherentes y adscriptas. Las relaciones con estos otros objetos podrán luego adscribir a los objetos otras clases de agencia, superpuestas a todas las anteriores ya acumuladas. Es decir, los objetos tienen el potencial de ser puntos de convergencia de una simultaneidad y multiplicidad de agencias, que serán efectivas de acuerdo a las interrelaciones en donde éstos participen (Figura 5).

\section{Los no-límites de las redes: los alcances}

Pensar los objetos en términos de redes de redes, de un fibrado multidimensional, plantea una dificultad cuando intentamos definir los límites de las mismas. Las redes no tienen un principio ni un fin (Latour 1998). La obtención de una materia prima para manufacturar un objeto, por ejemplo, ¿dónde comienza? ¿en la acción de levantar la materia prima? ¿en el acto de salir a buscar la materia prima? ¿en la intención del agente en ir a buscar la materia prima? ¿en su necesidad? ¿en la representación social de lo que es materia prima? ¿y dónde termina? Una propuesta es establecer los límites de un objeto o de una red allí donde no se hagan sentir más sus efectos, a la manera de los límites de los campos sociales que plantea Bourdieu (Bourdieu y Wacquant 1995; Laguens 2008). El efecto de la red de relaciones fijas que definen un objeto establece un límite neto allí donde se acaba su fisicalidad, como por ejemplo, la superficie de una vasija, la base, la boca, etc. El efecto de una vasija de almacenamiento en un contexto doméstico se puede limitar sólo a los habitantes de una casa o del recinto donde se ubique, o aquellos usuarios de su contenido, por ejemplo (Figura 6).

A esto se le suma otro problema de establecimiento de límites si pensamos que no existen sustancias, sino que lo que importan son las relaciones y sus efectos; por lo tanto, no habría algo que permita definir un adentro y un afuera, algo micro y algo macro, por ejemplo. Siguiendo con el ejemplo ¿dónde está límite de un área de actividad en un recinto si la materia prima fue traída desde afuera? ¿Hasta dónde llega un sistema de producción
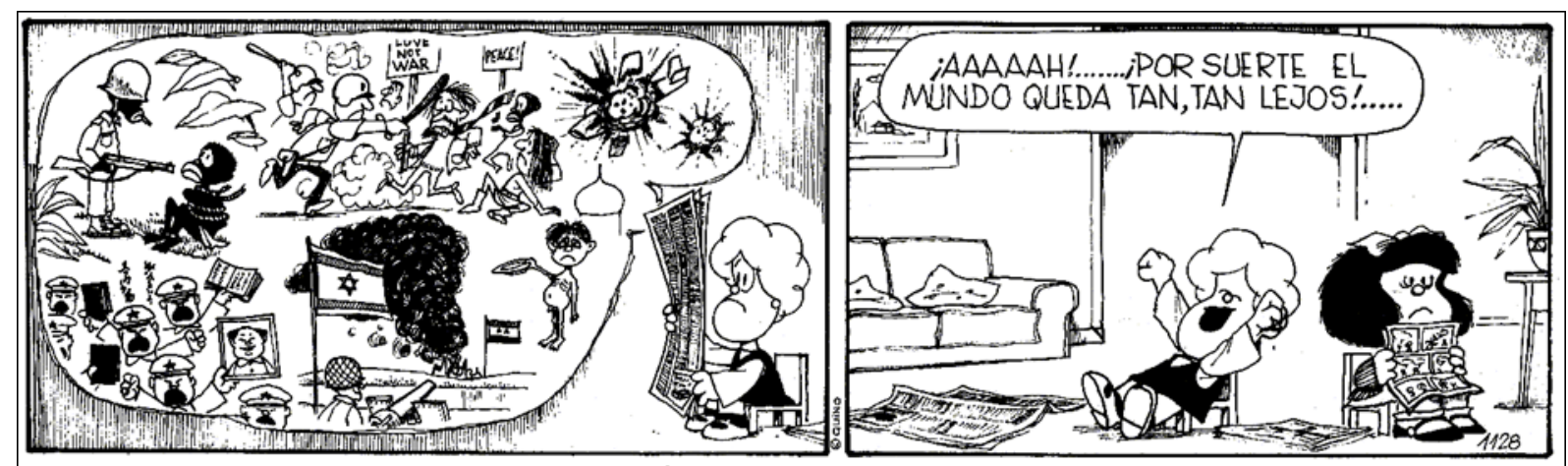

Cómic 5: Contextos I / Contexts II 

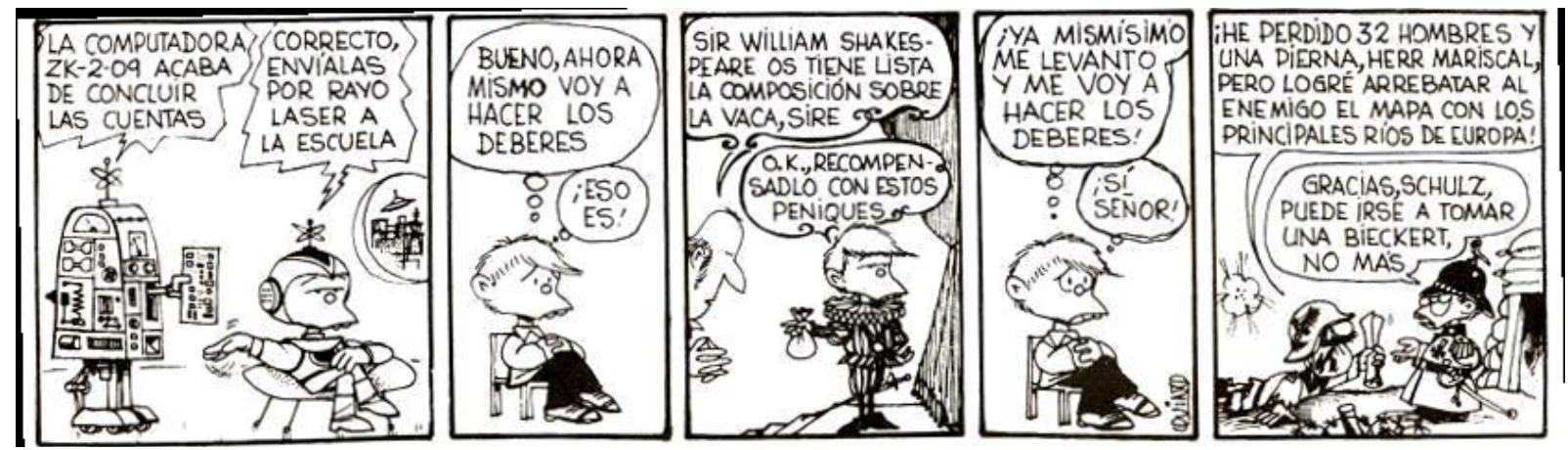

Figura 6. Contextos II / Figure 6. Contexts II.

tecnológico? ¿Dónde se acaba una estrategia? ¿qué define mejor una estrategia: las cosas o las relaciones? ¿Cuáles cosas sí y cuáles no?. En fin, más que límites podemos decir mejor que las redes de relaciones tienen alcances (Laguens 2008), es decir, posibilidades de tener mayor o menor efecto sobre otras entidades y redes de entidades humanas y no humanas gracias a sus relaciones y la multiplicidad y simultaneidad de agencias inherentes y adscriptas.

\section{Un contexto sin contexto}

Si estamos de acuerdo en que los objetos son efectos de tramas de relaciones de un fibrado multidimensional heterogéneo donde participan humanos y no humanos; interrelacionado en entramados de distinto alcance que no tienen un inicio y un fin claro, donde los objetos tienen posibilidades de agencia e incidencia, agencias que por su parte pueden ser múltiples y simultáneas, entonces ¿cómo podemos entender los contextos arqueológicos? ¿podemos seguir pensando en ellos como productos y subproductos de procesos? ¿podemos seguir pensando al contexto arqueológico como algo estático en base a distribuciones y asociaciones físicas en un espacio determinado, cuyo dinamismo fue dado por las acciones que le imprimían los humanos en el pasado?

Podríamos continuar pensando que sí, en la medida que sigamos sólo una de las múltiples hebras del fibrado de objetos y personas, como la de la obtención, manufactura, uso y descarte de un objeto o clase de objetos, limitada en espacio y tiempo. Tendemos a pensar que no, si pensamos que las distribuciones y proximidades físicas entre objetos es un fibrado heterogéneo de interrelaciones de distintos alcances.

Seguir sosteniendo una idea de contexto que limite las relaciones principalmente a aquellas físicas y de orden espacial (básicamente, de distancia) y a las de causalidad entre conducta y productos materiales (tanto en objetos como en sus disposiciones) en el registro arqueológico, es ignorar o desdibujar la multidimensionalidad y simultaneidad de las relaciones humanas con su mundo social y de los objetos.
Desde un punto de vista relacional, ya no hay contexto. No hay asociaciones, hay relaciones, no hay cadenas, hay redes, hay fibrados; no hay procesos, hay multiplicidad de agencias; no hay subproductos, hay efectos; no hay límites, hay alcances; no hay sustancias, hay interrelaciones, no hay esencias, hay formas estables; no hay conductas, hay prácticas. En un contexto relacional la idea de contexto arqueológico no tiene contexto. No hay contexto para el contexto.

Pero ¿cómo trabajamos si perdemos la idea de contexto, algo tan práctico e incorporado que nos permite "entender" el registro arqueológico? Decir que el contexto no es contexto no es decir que no haya registro arqueológico ni otra forma de capturar y entender los entramados pasados a la manera de un contexto. En un contexto relacional el contexto es un entorno o espacio de configuración.

Decir que no hay contextos es expresar simplemente un desacuerdo con una forma de inferencia y con el modelo textual (sea en perspectiva procesual o interpretativa) que implica pensar en términos de contextos, donde la relación de sentido principal se da a partir de la proximidad y el orden de las distribuciones y asociaciones en el espacio (como en los contextos schifferianos), tal como el de las palabras en un texto (como en los contextos textuales postestructuralistas).

Pero en realidad, como vimos, el registro ya no es tan neto, por el contrario, genera incertidumbre (Shanks y Hodder 1995); es más, podríamos decir que es vago, en el sentido filosófico del término, donde "la relación del sistema de representación con lo representado no es uno a uno, sino de uno a muchos" (Urtubey 2005: 74). De este modo no "leemos" el registro arqueológico, diríamos mejor que lo "observamos", lo "miramos" de una vez como un todo, como si fuera una imagen, una visualización en la cual, de forma inmediata, captamos muchas relaciones y dimensiones en un solo acto. No hacemos sólo una lectura lineal, sino que también hacemos inferencias (extraemos información) de manera más integral, de la misma manera en la que en la vida cotidiana hacemos inferencias usualmente sin pasar por la intermediación lingüística (como cuando miramos una 


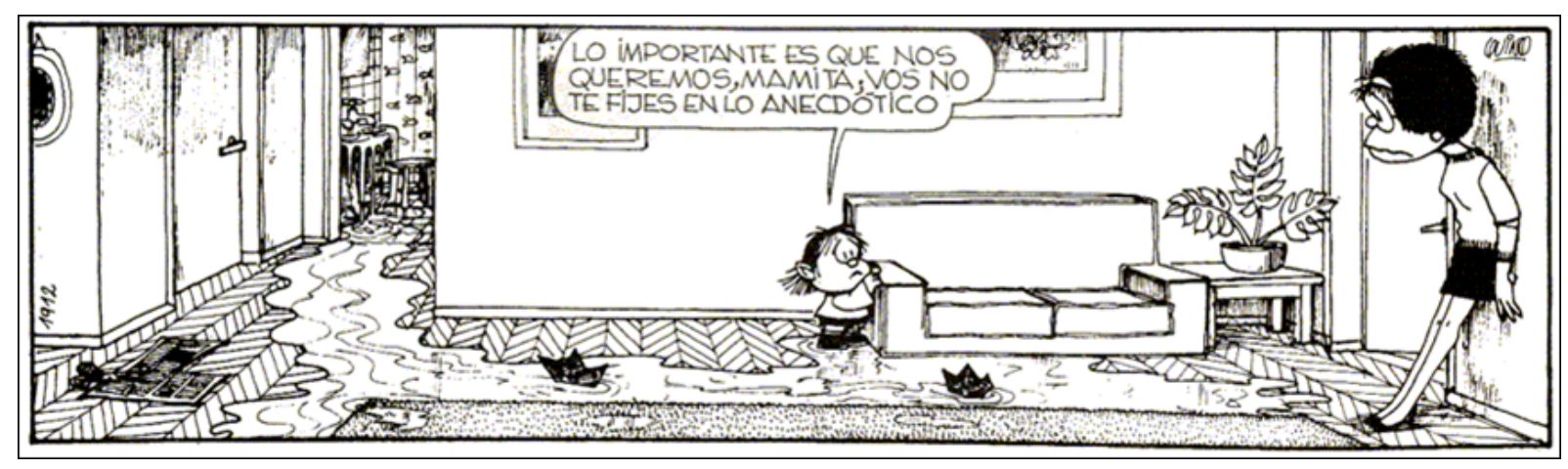

Figura 7. Inferencias / Figure 7. Inferences.

película, leemos un chiste u observamos el gesto de un desconocido).

Se trata de un sistema de inferencia heterogénea donde combinamos un modo de inferencia visual o diagramático con un modo lingüístico (Faas 2005:11); es una operación que involucra a la vez lectura textuales y lecturas visuales, diagramas y oraciones. Pensar el registro arqueológico contextualmente significa entonces autolimitar nuestra capacidad de conocimiento, tanto al reducir la multiplicidad de las redes en la linealidad de las cadenas de comportamiento, así como al estabilizar la dinámica de los contextos sólo como espacios de interacción y restringir la inferencia sólo al modo lingüístico.

\section{Los objetos en los no-contextos}

Hay que pensar que si definimos a los objetos por relaciones (estables o no), un cambio en el contexto de asociaciones, o del contexto arqueológico, implica un cambio en las relaciones. Luego, ese objeto cambia, ya no es el mismo, ha entrado en otra red. Por ende, debemos pensar a las relaciones contextuales como inestables, en oposición a las relaciones estables o inmutables de los objetos en sí. En este sentido relacional, nos encontramos con un contexto dinámico, un contexto relacional, que se aproxima más a la idea de un espacio de configuración.

Una configuración es una "disposición de las partes que componen una cosa y le dan su peculiar forma y propiedades anejas" (Diccionario de la Real Academia Española 2011), es decir, son partes en relación (disposición) que resultan en una forma con propiedades (Figura 7).

De ahí que iguales partes en una disposición distinta -un cambio en las disposiciones espaciales de un contextopodría implicar distintas propiedades, es decir, distintas cosas (cosas en el sentido general de entidades, no necesariamente materiales). En matemática se habla de un "espacio de configuración" como un espacio de estados posibles; uno entre otros posibles.

Estos espacios de configuración, son en sí también una red, un fibrado, con distintas posibilidades de estabilidad, de acuerdo a los agentes y las prácticas involucradas 5 . Son, como diría Latour, marcos para la interrelación: una red compleja y diversa de personas, espacios y tiempos por detrás de las relaciones (Latour 1996: 231). Las redes son así a la vez tramas y marcos de las relaciones.

Preferimos definir a estos marcos situacionales de las relaciones como entorno, el conjunto de condiciones extrínsecas necesarias que facilita que las cosas sean o se relacionen de cierta forma. Tal es el caso, por ejemplo, cuando hablamos de un entorno propicio para algo, del entorno Windows, del entorno doméstico.

Los objetos, como efectos de redes, tendrán ciertos alcances en estos entornos, que llegarán allí hasta donde sientan sus efectos otros elementos. Este conjunto de elementos que informan sobre el alcance de un objeto es lo que se conoce como contorno, como, por ejemplo, el contorno de una figura, el contorno de un territorio, el contorno de un área de actividad o de un sitio, más allá del cual no se siente su efecto.

En síntesis, desde una perspectiva relacional, podemos re-pensar ahora al contexto como un espacio de configuración que funciona como un entorno donde los objetos y sus relaciones con otras cosas y personas alcanzarán distintos contornos. Las variaciones en las relaciones, en los agentes intervinientes (humanos y no humanos) configurarán distintos entornos y trazarán distintos contornos de las redes (en términos tradicionales, habrían definido distintos contextos).

Una buena manera de ejercitar una mirada relacional de este tipo es a través de un estudio etnoarqueológico que realizamos sobre la fabricación de chicha por parte de migrantes bolivianas en un entorno urbano (la ciudad de Córdoba, Argentina) (Pazzarelli y Vargas 2008). En él observamos que muchos espacios del patio, casa

\footnotetext{
${ }^{5}$ Aquí jugarán un rol importante los humanos - en nuestra concepción asimétrica - ya que si bien esos estados posibles estarán dados por las potencialidades de incidencia de los objetos, será muy importantes las estrategias y recursos materiales e inmateriales puestos en juego, las disposiciones de los agentes materializadas en las prácticas, en función de su posición en el espacio social históricamente situado
} 
y barrio de las chicheras entraban en relación a partir de la puesta en práctica de una receta, configurando un espacio, un contorno (aun sin continuidad física), que permitió que la elaboración de la bebida resultara efectiva. Los objetos utilizados (baldes y tachos de plástico) referían a los materiales disponibles en el entorno de la ciudad, pero habían sido elegidos en función de su similitud morfológica y funcional con aquellos (de cerámica) utilizados en Bolivia, con lo que no hacían sino relacionarse, a través de su red de relaciones internas y fijas, con aquellos otros objetos "originales" que usualmente se utilizan en la elaboración: así, los efectos de las vasijas cerámicas bolivianas llegaban hasta los baldes de plástico utilizadas en Córdoba, a través de la puesta en práctica de un proceso de elaboración específico. Al mismo tiempo, estos objetos (de plástico) y el patio en donde se cocinó, se relacionaron con otras casas, cocinas, objetos y personas que acudieron al lugar a participar del evento, incorporando en el mismo a sus propios objetos y mano de obra. Es decir, la práctica (y sus efectos) superó la inmediatez del lugar físico de las acciones (el fogón, las ollas, el patio) y generó un contorno más amplio: se amplió a otras habitaciones y a otras familias.

En otro orden, la materia prima utilizada (wiñapu = harina de maíz germinado) había sido traída especialmente desde Bolivia y nunca dejó de estar vinculada a su lugar de origen. ¿Qué queremos decir con esto? Que el wiñapu no fue concebido sólo como maíz germinado y convertido en harina (es decir, concebido sólo a partir de su red de relaciones fijas e internas que definían su materialidad y sus límites espaciales); por el contrario, sólo podía ser definido en función de otra red, más amplia, de relaciones que lo configuraban como tal: era wiñapu boliviano, era wiñapu a ser mezclado, era wiñapu para chicha, era wiñapu para la fiesta. Se convirtió en un objeto cuyos efectos propiciaron que la receta resultara efectiva: el hecho de ser materia prima boliviana ("original") produjo un entorno que permitió que la chicha preparada fuera considerada "buena" y como la de allá (Pazzarelli y Vargas 2008).

El ejemplo anterior nos presenta una situación donde las relaciones que se establecen entre los objetos, las personas y sus prácticas superan cualquier idea acerca de la espacialidad de un contexto. En definitiva, la chicha se fabricó en un contexto relacional, materialmente heterogéneo y espacialmente discontinuo, de contornos difusos y extra muros, relacionando simultáneamente distintas agencias humanas y materiales, al tiempo que vinculaba espacios locales con otros más lejanos. Podemos decir que la chicha, como el objeto producido, fue un efecto de toda esa red.

Con este criterio ampliado de contexto como un espacio de configuración relacional, junto con el de objetos en redes y las posibilidades de agencias humanas y no humanas, como ya dijimos, no podemos pensar luego a los objetos y a sus contextos materiales sólo como el producto de acciones o conductas y partes de un proceso, pues ya no hay un inicio ni un fin, no hay una cadena de comportamiento, sino un fibrado de interrelaciones superpuestas, donde cada cruce en el entramado es un lugar de mediación entre otras tantas acciones y relaciones.

¿Dónde reside la importancia de poder romper con las limitaciones del contexto? Quizás en que nos permite investigar con más detalle y precisión las formas por las cuales llegaron a existir las asociaciones que encontramos en el registro arqueológico y cómo son atribuidos, estabilizados o fijados los roles, funciones, categorías, sentidos y posiciones relativas de las personas y los objetos en el mundo material. Una de las metas de investigar en estos términos puede ser entender cómo son construidas, mantenidas y transformadas diferentes redes entre humanos y no humanos, tanto en el pasado como en el presente.

\section{Manufactura y uso en red}

A través del análisis situacional y relacional de un conjunto de vasijas cerámicas ordinarias mostraremos ahora las potencialidades de aplicación de estos conceptos para el estudio de la tecnología cerámica. Mediante el seguimiento de las redes, analizaremos los distintos agentes involucrados, su multiplicidad y simultaneidad, los recursos materiales e inmateriales puestos en juego, los puntos de mediación y de intersección entre las redes, sus alcances y la definición del entorno de las prácticas involucradas en las piezas analizadas (entre las que llegaremos a las de su distribución y uso).

Como procedimiento trataremos de seguir las redes involucradas a lo largo de toda su extensión en el espacio y en lapso de tiempo (Murdoch 1997: 332). Este acto no requiere que se especifiquen con anterioridad distintos niveles de análisis, ni que se adopten con anticipación distintos repertorios para entidades que aún no han logrado forma e identidad en nuestra categorizaciones (Ibídem: 335), como puede ser partir de la manufactura, uso y descarte como categorías analíticas.

Una de las primeras dificultades en este tipo de análisis es plantear un punto por el cual empezar. Si una red de relaciones no tiene principio ni fin, podemos entrar al entramado por donde queramos o por aquél lugar que nos resulte más pertinente para nuestro tema de estudio. En este caso, decidimos partir de una clase de objetos: una serie de vasijas de cerámica ordinaria utilizadas en entornos domésticos del siglo VI d.C. en el Valle de Ambato, Catamarca, en Argentina. Se ha argumentado que este valle, durante los siglo VI a XII de nuestra era, ha sido el punto de partida del proceso de profundización y consolidación de desigualdades sociales basadas en el culto, en el intercambio de bienes simbólicos y en 
jerarquías sociales probablemente hereditarias que caracterizó a la cultura de "La Aguada", proceso al que luego se habrían incorporado las zonas aledañas (Heredia 1998, González 1998, Pérez Gollán 1991, 1994, Laguens y Bonnin 1996). Los objetos a los que nos referiremos aquí estuvieron presentes a lo largo de toda la secuencia temporal considerada y acompañaron los cambios sociales mencionados (Gastaldi 2010).

A partir de ciertas propiedades y relaciones estables podemos caracterizar a dichas piezas por ser restringidas de contorno compuesto o inflexionado, con una sección inferior subglobular de base cónica (por lo que son inestables y necesitan de apoyo para mantenerse erguidas) y una superior subcilíndrica, con paredes convergentes o subtroncocónicas, con labio recto y un punto de inflexión que separa el cuello del cuerpo, sin asas. En ocasiones, algunas de ellas tienen 'baños' negros sobre su superficie interior, a la manera de 'impermeabilizantes'. (Bedano et al 1976; Gastaldi 2010). En cuanto a sus características formales, presentan una altura que oscila entre los 253 $\mathrm{mm}$ y los $783 \mathrm{~mm}$, aunque la mayoría de ellas se ubican entre los $550 \mathrm{~mm}$ y los $600 \mathrm{~mm}$; sus diámetros de boca oscilan entre los $131 \mathrm{~mm}$ y los 375 mm (Gastaldi 2010). Poseen un volumen promedio de 76,57 litros, aunque pueden alcanzar los 261 litros, un dato que a estas vasijas en el conjunto de recipientes con mayores capacidades de contención en el valle. Sus bocas amplias permite que su contenido sea de fácil acceso y que posean una alta accesibilidad; no obstante, debido a su tamaño y a la inexistencia de asas, poseen una baja transportabilidad (Ibídem). En el cuello suelen contar con la representación de un rostro humano, a veces con modelado de la nariz como un gancho hacia arriba, con cejas, orejas y ojos al pastillaje, acompañado con pintura roja, negra y blanca; otras veces el rostro está sólo pintado; otras veces son lisas (Figura 8(. Las paredes son gruesas (de hasta $2 \mathrm{~cm}$ de espesor en las más grandes), de pasta semicompacta con antiplástico grueso, de cocción oxidante (usualmente conocida como cerámica "ordinaria" o "tosca").
Estas vasijas se encuentran en distintos espacios de configuración en el registro arqueológico, tanto en sitios de vivienda comunes (Assandri 1991; Juez 1991) como en sitios especiales, tales como centros ceremoniales (Iglesia de los Indios, Gordillo 2005) o residencias de jerarquía (Piedras Blancas, Laguens 2005). En estos contextos de relaciones, se las halla insertas en por lo menos dos entornos distintos: en el interior de recintos techados y en el interior de patios, ya sea bajo galerías o no, apoyadas en el piso o sostenidas mediante estructuras de piedras, y en situaciones de abandono de los sitios, hecho puesto de relieve por la caída de la techumbre quemada sobre estos objetos. En ambos casos, se las ha encontrado tanto vacías, como con restos carbonizados de semillas (Gordillo y Ares 2005), con restos óseos humanos (Juez 1991). Otros análisis permitieron comprobar que se habrían vinculado tanto con recursos animales como vegetales (Pazzarelli 2006).

A partir de esta pequeña síntesis intentaremos comenzar a recorrer algunas de las fibras que se entrelazan a través de estos objetos con otras entidades y agencias.

Volvamos a los objetos en sí. Encontramos en sus atributos una red de relaciones internas, fijas (y humanamente fijadas en la manufactura como práctica) que los definen como entidades aislables e identificables, marcando a través de sus efectos materiales los límites físicos de las piezas o su contorno, en el sentido de los alcances descrito arriba. A su vez, consideramos a estos objetos como un colectivo, como una clase con propiedades comunes y relaciones homólogas fijas, las que, justamente en su inmutabilidad, nos permiten identificarlas y agruparlas como tales. Sin duda su fisicalidad es resultado de una práctica individual socialmente inscripta (la fabricación de vasijas grandes antropomorfas de tradición tricolor) con posibilidades de agencias directas de su creador, así como secundarias por su carga estética o por las prácticas en las cuales se insertaron.
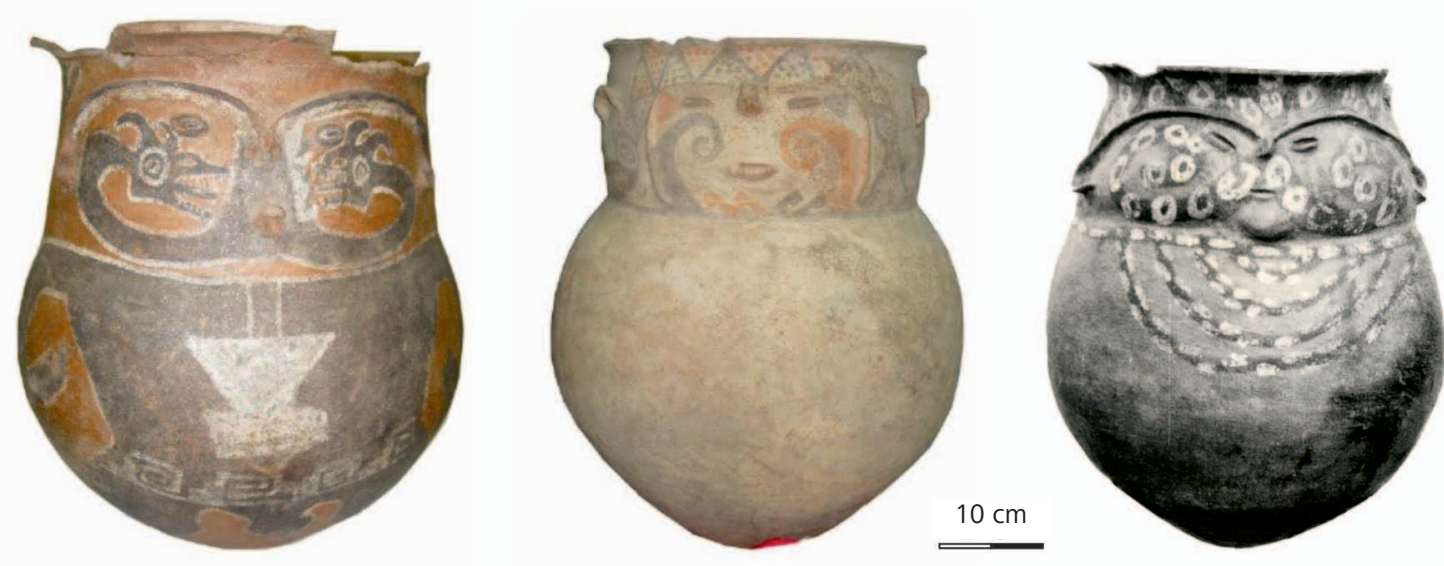

Figura 8. Serie de vasijas de almacenamiento provenientes de distintos sitios del Valle de Ambato.

Figure 8. A number of storage vessels from different sites in the Valley of Ambato. 
Estas redes de relaciones durables (que hacen que las vasijas sean así y no de otra forma) nos abren una serie de hebras del fibrado en el que se hallan insertos estos objetos ya de por sí, sólo como tales. Son redes muy fáciles de imaginar o reconstruir para cualquier arqueólogo sin necesidad de recurrir a ningún entorno o contexto relacional particular, que no es necesario enumerar o describir aquí; no obstante, sí debemos recordar que es una red de relaciones, una red de redes, y no un proceso, una red en donde juegan materiales, sentidos, personas, representaciones sociales, códigos, actividades, energía, trabajo, conocimientos, técnicas, tiempo, hábitos, habitus, memorias sociales, memorias operativas, habilidades.

Es probable que todo esto haya formado parte de las redes involucradas en cada vasija, quizás en el momento en que el artesano las concibió como tal y las manufacturó, pero luego, sin duda, se insertaron en prácticas diferentes, formaron parte de otros entornos y sus efectos pudieron llegar a otros espacios. El objeto producido ya no es sólo esa red de relaciones internas y fijas. Comienza su coreografía (o su "enriedo").

Sin salir de los contornos del objeto, podemos analizar ciertos atributos que son efectos de otras prácticas (y redes) que los han alcanzado, como aquellas vinculadas con las prácticas domésticas, sus diversos usos, emplazamientos y desplazamientos, por ejemplo. Por ejemplo, a partir del análisis de huellas de uso realizado sobre estas vasijas (Gastaldi 2010), sobre la superficie externa en la región de la base se encontró una serie de parches, o conjuntos indefinidos de huellas de desgaste que han removido parte del material, junto con algunas estrías en los sectores medios del cuerpo en dirección longitudinal u oblicua al eje de rotación. Ambos tipos de rastros se asocian con movimientos de inclinación de la vasija, facilitando el vertido o bien el acceso a su contenido cuando no estaban llenas. Por otro lado, el conjunto de huellas presentes en el interior de la vasija, en la zona del borde y repartidas en toda la superficie interna (evidentes como estrías y antiplástico sobresaliente con superficies redondeadas), también se asocia con acciones relacionadas con la manipulación del contenido y con la introducción de algún tipo de objeto para tal fin (Ibídem). Estos contenidos podrían haber sido de origen vegetal u animal (Pazzarelli 2006), aunque probable sugerir una tendencia más cercana a los primeros, tal como lo permiten suponer los análisis cromatográficos y de identificación de gránulos de almidón afines a Zea mays en una vasija de este tipo (Pazzarelli 2011).

En cuanto al objeto introducido para manipular su contenido, desconocemos cuál pudo haber sido (cucharas o alguno similar), que fueron frotadas contra las paredes y dejaron estrías. Por la orientación y la clase de marcas internas y externas, las vasijas parecieran haberse utilizado para manipular un contenido líquido; las erosiones internas que presentan varias de ellas podrían vincularse con los procesos de fermentación de bebidas, posiblemente chicha (Gastaldi 2010).

¿Qué significa esto más allá de las acciones particulares que generaron los rastros de utilización, es decir, de su uso efectivo como contenedores? Que las vasijas, a través de otras prácticas de producción (es decir, no sólo de aquella vinculada a su manufactura sino también de la producción agrícola, de producción de alimentos, entre otras) participaron en otras redes económicas y sociales (tales como redes de distribución y consumo, redes de intercambio, de dones y contradones, etc.). Éstas incluyeron prácticas particulares que implicaron acciones como su manipulación, así como el llenado y vaciado, por parte de agentes humanos en distintos entornos sociales (de acuerdo a la configuraciones espaciales encontradas en diferentes clases de sitios que ya mencionamos), con alcances que superan el entorno doméstico y atraviesan distintos agentes en diferentes posiciones en el espacio social, a la par que involucran diversos objetos, espacios y tiempos, continuos como discontinuos (como, por ejemplo, los distintos espacios domésticos, la organización cotidiana de las actividades, los tiempos involucrados en los ciclos agrícolas). Todo ello complejiza y diversifica las redes: las vasijas son articuladas simultáneamente en prácticas diversas, permitiendo o inhibiendo la reproducción de estructuras, facilitando o determinando el ejercicio de ciertas formas de hacer las cosas.

Veamos otra hebra como ejemplo. Cada vasija tiene un volumen limitado (un promedio aproximado de 76 litros) y se las encuentra en todas las clases conocidas de sitios, más allá de la jerarquía social asociada a los mismos; además, todas se remontan a una tradición tecnológica proveniente de las sociedades anteriores a Aguada en el valle. Desde este punto de vista, eran en un recurso material tradicional, compartido, de acceso no restringido a distintos estratos de la sociedad (Laguens 2006). Podemos decir también que participaban en redes de producción, distribución y uso similares, en una aparente igualdad.

No podemos decir lo mismo, en cambio, en lo que refiere a su acumulación. La cantidad de vasijas halladas varía en las distintas clases de sitios: en general, cuanto mayor el tamaño de los asentamientos, hay más cantidad de vasijas y, por lo tanto, mayor la cantidad de recursos acumulados (Pazzarelli 2006, 2009). Pero esta mera relación proporcional no remite sólo a una cuestión de espacio físico en donde se pueden emplazar más o menos vasijas, sino que, en un contexto social no igualitario, refiere a las posibilidades de acceso a los bienes materiales y al mismo espacio también como bien o recurso, entendiendo a la viabilidad de posesión y acumulación de distintas clases de capitales como un 
medio de diferenciación entre los individuos y grupos de individuos (Bourdieu 1984, 1986, 1988, Laguens 2006; Laguens y Bonnin 2005). Con ello, estamos diciendo entonces que las vasijas, en su uso, se remontan a entramados sociales caracterizados por relaciones de desigualdad y son dotadas de una agencia secundaria que contribuye a reproducir, manteniendo o ampliando, las diferencias inscriptas social y culturalmente entre las personas. En cierto sentido, al participar a la par en otra serie de entramados no tecno-económicos (para diferenciarlos de alguna manera de los de su cadena de comportamiento) las vasijas, en las mismas trayectorias de distribución, uso y consumo, están materializando las diferencias sociales.

En otras palabras, se encuentran atravesadas por la red de relaciones de un entorno desigual que, al tiempo que las define como vasijas que almacenan, las inscribe en una práctica que permite sea reproducido ese mismo entorno. Se trata de un juego en el que personas, objetos (vasijas) y relaciones se construyen y definen mutuamente, a través de sus diferentes tipos de agencias, otorgando movimiento al fibrado.

\section{Palabras finales}

Al pensar a los objetos en sus entramados heterogéneos hemos podido acceder a una dimensión relacional, simultánea con otras, en la que objetos y humanos se construyen mutuamente como agentes particulares de un orden social (en este caso, internamente diferenciado).

Se trata de una dimensión no material, aunque materializada a través de prácticas, configuraciones espaciales diferenciales, entornos sociales particulares y contornos de distintos alcance en el espacio y en el tiempo, que otorgan "profundidad" y movimiento al fibrado multidimensional en el que se insertan los objetos cerámicos.

A ello se superponen otras dimensiones relacionales, las que usualmente podríamos describir como tecnológicas, económicas, ideológicas, etc, que se entrelazan con otras prácticas como las de manufactura, distribución, consumo, uso y descarte (las que usualmente podríamos describir a través de una cadena de comportamiento), en un complejo, pero aprehensible, entramado sociomaterial multidimensional.

\section{Agradecimientos}

Este trabajo fue presentado y discutido en la IV Reunión Internacional de Teoría Arqueológica en Suramérica, desarrollada en julio de 2007 en la ciudad de San Fernando del Valle de Catamarca (Argentina). Las ilustraciones de Mafalda pertenecen al libro de Quino,
Todo Mafalda de Ediciones de la Flor.

\section{Bibliografía}

Assandri, S. 1991. Primeros resultados de la excavación en el sitio Martínez 1 (Catamarca, Argentina). Publicaciones del CIFFYH 46: 53-86.

Assandri, S. 1999. Procesos de complejización social y organización espacial en el Valle de Ambato (Catamarca, Argentina). Universidad Internacional de Andalucía. Tesis de Maestría en Arqueología Social,

Binford, L. 1980. Willow smoke and dogs'tails: huntergatherer settlement systems and archaeological site formation. American Antiquity 45 (1): 4-20

Bourdieu, P. 1984. Sociología y Cultura, Grijalbo, México

Bourdieu, P. 1986. The forms of capital. En Richardson, J. (ed.), Handbook of Theory and Research for the Sociology of Education: 241-258. Greenwood, Nueva York.

Bourdieu, P. 1988. Espacio social y poder simbólico. P. Bourdieu, Cosas dichas, Gedisa, Buenos Aires.

Bourdieu, P. y L. Wacquant. 1995 Respuestas: por una antropología reflexiva, Grijalbo, México.

Breslau, D. 2000. Sociology after Humanism: A Lesson from Contemporary Science Studies. Sociological Theory 18 (2): 289-307.

Descola, P. 2005.Anthropologie de la nature. http://www. college-de-france.fr/media/anthrop/UPL35672_descola_ cours0405.pdf (Última consulta: 24/10/2011).

Emirbayer, M. 1994. Network Analysis, Culture, and the Problem og Agency. American Journal of Sociology 99 (6): 1411-1454.

Emirbayer, M. 1997. Manifesto for a relational Sociology. American Journal of Sociology 103 (2): 281-317.

Emirbayer.M. y A. Mische. 1998 What is Agency?. American Journal of Sociology 103 (4): 962-1023.

Faas, H. 2005. Implicación visual y heterogénea. H. Faas y L. A. Urtubey, Temas de razonamiento aproximado e inferencia heterogénea: 11-23, CIFFyH, Universidad Nacional de Córdoba.

Fuchs, S. 2001. Betond Agency. Sociological Theory 19 (1): 24-40.

Gastaldi, M. 2010. Cultura Material, Construcción de 
Identidades y Transformaciones sociales en el Valle de Ambato durante el Primer milenio d. C. Facultad de Ciencias Naturales y Museo, Universidad Nacional de la Plata, Argentina, 565 páginas. Tesis Doctoral.

Gibson, J. J. 1971. More on Affordances. E.S. Reeds y R. Jones, Reasons for Realism, Cap. 4.9, pp. 406-408, Lawrence Erlbaum Associates Inc.

González, A. R. 1998. La cultura de la Aguada. Arqueología y Diseños, Filmediciones Valero, Buenos Aires.

Gordillo, I. y L. Ares. 2005. Ingresando a los patios de La Rinconada. Ambato-Catamarca. Martín S., M.E. Gonaldi, S. R. Ferraris y A. R. Giordano, La cultura de la Aguada y sus expresiones regionales: 211-221. EUDELAR, La Rioja.

Hitchings, R. 2003. At home with someone nonhuman. Home Cultures 1 (2): 169-186.

Hodder, I. 1982. Symbols in Action. Cambridge University Press

Hodder, I. 1994. Interpretación en Arqueología. Corrientes actuales. Editorial Crítica, Barcelona, 2da edición.

Hodder, I. 1999. The Archaeological Process. An Introduction. Blackwell Publishers, Oxford.

Ihde, D. 2006. Material Hermeneutics. http://traumwerk. stanford.edu:3455/Symmetry/746 (Última consulta: 24/10/2011).

Juez, S. 1991. Unidad arqueológica Rodeo Grande, Valle de Ambato: excavación en el sitio Martínez 2. Publicaciones del CIFFYH 46: 87-110.

Heredia, O. 1998. Proyecto: investigaciones arqueológicas en la región del Valle de Ambato (dto. Ambato, provincia de Catamarca). Estudios 10: 7182. Centro de Estudios Avanzados de la Universidad Nacional de Córdoba.

Laguens, A. 2005. Arqueología de la diferenciación social en el valle de Ambato, Catamarca, Argentina (s. II - VI d.C.): el actualismo como metodología de análisis. Relaciones Sociedad Argentina de Antropología XXIX: 137-162.

Laguens, A. 2006. Espacio social y recursos en la arqueología de la desigualdad social. Gnecco C. y C. H. Langebaek, Contra la tiranía tipológica en arqueología: una visión desde Sudamérica: 99-119. Uniandes, Bogotá.

Laguens, A. 2008. Objetos en objetos: hacia un análisis relacional de lo estético en arqueología. Icónica Antiquitas julio-diciembre: 1-11.Universidad de Tolima, Bogotá

Laguens, A. y M. Bonnin. 1996. Evaluación de serie de fechados radiocarbónicos del Valle de Ambato, Catamarca. Publicaciones del CIFFYH 48: 65-101.

Laguens, A. y M. Bonnin. 2005. Recursos Materiales y Desigualdad Social en la Arqueología de AmbatoCatamarca. En Martín S., M.E. Gonaldi, S. R. Ferraris y A. R. Giordano (eds.): La Cultura de la Aguada y sus Expresiones Regionales: 23-33. EUDELAR, La Rioja.

Laguens, A. y M. Gastaldi. 2008. Registro material, fisicalidad, interioridad, continuidad y discontinuidad: posiciones y oposiciones frente a la naturaleza y las cosas. En Jackson, D., D. Salazar y A. Troncoso, Puentes hacia el pasado: reflexiones teóricas en arqueología: 169-189. Sociedad Chilena de Arqueología, Santiago de Chile.

Latour, B. 1996. On Interobjectiviy. Mind, Culture and Activity 3 (4): 228-245.

Latour, B. 1998. On actor-network theory: a few clarifications. http://www.nettime.org/Lists-Archives/ nettime-I-9801/msg00019.html (Última consulta: 24/10/2011).

Law, J. 1992. Notes on the Thoery of teh Actor network: Ordering, Strategy and Heterogeneity. http://www.lancs. ac.uk/fass/sociology/papers/law-notes-on-ant.pdf (Última consulta: 24/10/2011).

Law, J. 1997. Topology and the naming of Complexity. http://www.lancs.ac.uk/fass/sociology/papers/lawtopology-and-complexity.pdf (Última consulta: 24/10/2011)

Law, J. 2000. Objects, Spaces and Others. http://www. lancs.ac.uk/fass/sociology/papers/law-objects-spacesothers.pdf. (Última consulta: 24/10/2011)

Layton, R. 2003. Art and Agency: a reassessment. Journal of the Royal Anthropological Institute 9: 447-464.

Lemonnier; P. 1986. The Study of Material Culture Today: Toward an Anthropology of Technical Systems. Journal of Anthropological Archaeology 5 (2): 147-186.

Lemonnier; P. 1992. Elements for an Anthropology of Technology. Anthropological Papers, Museum of Anthropology, University of Michigan 88: 1-24.

Murdoch, J. 1997. Towards a geography of heteroeneous associations. Progress in Human Geography 21 (3): 321337.

Pazzarelli, F. 2006. Prácticas domésticas de 
almacenamiento y consumo en contextos arqueológicos de desigualdad social (Valle de Ambato, Catamarca). Facultad de Filosofía y Humanidades, Universidad Nacional de Córdoba, Argentina, 195 páginas. Tesis de Licenciatura en Historia.

Pazzarelli, F. 2009. En el interior de las vasijas... Almacenamiento y consumo en un contexto desigual (Valle de Ambato, Catamarca). Bourlot, T., Bozzuto, D., Crespo, C., Hecht, A. C. Kuperszmit, N., Entre pasados y presentes II: estudios contemporáneos en ciencias antropológicas: 289-304. Fundación de Historia Natural Félix de Azara, Bs. As.

Pazzarelli, F. 2011. Una aproximación a la transformación de recursos en Piedras Blancas (Ambato, Catamarca, S X-XI DC) desde los análisis químicos. Relaciones de la Sociedad Argentina de Antropología 36. En prensa.

Pazzarelli, F. y G. Vargas Ibarra. 2008. ¿Cómo hacer chicha en Córdoba? Reflexiones acerca de las implicancias políticas y materiales de la producción de chicha por inmigrantes bolivianos. Revista del Museo de Antropología 1 (1): 29-40.

Pérez Gollán, J. A. 1991. La cultura de La Aguada vista desde el Valle de Ambato, Publicaciones del CIFFYH 46: 157-173.

Pérez Gollán, J. A. 1994. El proceso de integración en el Valle de Ambato: complejidad social y sistemas simbólicos. Rumitacana 1: 33-41.

Quino (Joaquín Salvador Lavado). 1993. Toda Mafalda. Ediciones de La Flor, Buenos Aires.

Real Academia Española. 2011. Diccionario. http://buscon.rae.es/drael/SrvltConsulta?TIPO_ BUS=3\&LEMA=configuraci\%C3\%Bn. (Última consulta: 24/10/2011).

Shanks, M. 2006. From a postprocesual to a symmetrical arcaheology. http://traumwerk.stanford.edu:3455/ Symmetry/822 (Última consulta: 24/10/2011).
Shanks, M. e I. Hodder. 1995. Processual, postprocessual and interpretative archaeologies. I. Hodder, M. Shanks, A. Alexandri, V. Buchli, J. Carman, J. Last y G. Lucas, Intepreting Arcaheology. Finding meaning in the past: 3-29. Routledge, Londres.

Schiffer, M. B. 1972. Archaeological Context and Systemic Context. American Antiquity 37: 156-165.

Schiffer, M. B. 1976. Behavioral Archaeology. Academic Press, New York.

Smith, R. G. 2003. World city topologies. Progress in Human Geography 27 (5): 561-582.

Tirado Serrano, F. y M. Doménech i Argemí. 2005. Asociaciones heterogéneas y actantes: el giro postsocial de la teoría del actor-red. En Sánchez-Criado, T., Tecnogénesis. La construcción técnica de las ecologías humanas vol 1: 41-78. AIBR, Madrid.

Urtubey, L. A. 2005. Algunas consideraciones sobre la autoconsistencia de los predicados difusos. H. Faas y L. A. Urtubey, Temas de razonamiento aproximado e inferencia heterogénea: 74-83. CIFFyH, Universidad Nacional de Córdoba.

Verbeerk, P. 2003. Material Hermeneutics. Techné 6 (3): 91-95.

Verbeerk, P. y P. Kockelkoren. 1998. The Things That Matter. Dessign Issues 14 (3): 28-42.

Webmoor, T. 2006. Un giro más tras el "giro social". El principio de la simetría en arqueología.

http://humanities/ab.stanford.edu/30/1090 (Última consulta: 24/10/2011).

Witmore, C. 2006. "A past no longer past» Some implications for a symmetrical archaeology. http:// traumwerk.stanford.edu:3455/Symmetry/1040 (Última consulta: 24/10/2011). 